\title{
Pricing expropriation risk in natural resource contracts - A real options approach
}

\author{
Eduardo S. Schwartz \\ UCLA Anderson School of Management and NBER \\ Anders B. Trolle \\ Copenhagen Business School
}

\begin{abstract}
We develop a model for pricing expropriation risk in natural resource projects, in particular an oil field. The government is viewed as holding an American-style option to expropriate the oil field, but facing the following three possible expropriation costs: A state-run company may produce oil less cost-efficiently than a private firm, the government may have to pay a compensation to the firm, and an expropriation may trigger lower investor confidence negatively affecting the overall economy. The dynamics of key variables - the spot price, futures prices and volatility - is described by a model proposed and estimated in Trolle and Schwartz (2007). For reasonable parameter values and under market conditions not too different from what has been seen in recent years, the value of the expropriation option can be substantial.
\end{abstract}

JEL Classification: G13

Keywords: Real options, crude oil contracts, expropriation risk

This version: January 2008

This paper was prepared for the November 2007 conference "Populism and Natural Resources" at Harvard University. We thank Robert Pindyck (the discussant), Federico Sturzenegger, William Hogan and seminar participants for extensive comments. Anders Trolle thanks the Danish Social Science Research Council for financial support. Eduardo Schwartz: UCLA Anderson School of Management, 110 Westwood Plaza, Los Angeles, CA 90095-1481. E-mail: eduardo.schwartz@anderson.ucla.edu. Anders Trolle: Copenhagen Business School, Solbjerg Plads 3, A5, DK-2000 Frederiksberg, Denmark. E-mail: abt.fi@cbs.dk 


\section{Introduction}

There are many dimensions to the study of expropriation risk in natural resources including political, environmental, sociological and economic issues. In this paper we abstract form most of these aspects and concentrate on some of the important economic tradeoffs that arise from the government having an option to expropriate the resource.

We show how to use the real options approach to value a natural resource project, in particular an oil field, exposed to expropriation risk. ${ }^{1}$ We view the government as holding an option to expropriate the oil field. ${ }^{2}$ The government faces a tradeoff. By expropriating, it will receive all future profits from the oil field rather than just a fraction of profits through taxes. However, there are also costs associated with expropriating, and we consider three such costs. Firstly, a state-run company may produce oil less cost-efficiently than a private firm. Secondly, the government may have to pay a compensation to the firm. Thirdly and perhaps most importantly, there may be "reputational" costs in the sense that investors will perceive the government as being more likely to renege on other contracts as well, and will therefore be more reluctant to make new investments in the country, particularly in capital intensive natural resource projects, negatively affecting the overall economy.

The dynamics of the crude-oil spot price, futures prices and volatility that we use for the analysis is described by a model proposed in Trolle and Schwartz (2007). This model has several attractive features. Futures prices are driven by two factors, with one factor affecting the spot price of the commodity and another factor affecting the slope of the futures curve though the cost of carry. Futures (and spot) price volatility is stochastic and is driven by a third factor which implies that options are driven by three factors and that the model features "unspanned stochastic volatility" (that is, volatility risk cannot be completely hedged by trading in futures contracts) consistent with the data. The model has quasi-analytical prices of European-style options on futures contracts enabling fast calibration to liquid plain-vanilla exchange-traded derivatives. Finally, the dynamics of the futures curve can be described in terms of four state variables (three stochastic and one deterministic) jointly constituting an affine state vector which makes the model ideally suited for pricing complex commodity derivatives, including

\footnotetext{
${ }^{1}$ For a comprehensive exposition of the real options approach to valuation, see Dixit and Pindyck (1994).

${ }^{2}$ Throughout the paper, we consider the risk of the state taking over the entire oil field. The framework could be modified to consider the risk of a partial expropriation through a forced renegotiation of existing contracts involving, for instance, an increase in taxes or the state taking a certain stake in the oil field.
} 
real options, such as the expropriation option, by simulation. ${ }^{3}$

In Trolle and Schwartz (2007), the model was estimated and tested on NYMEX ${ }^{4}$ crude-oil derivatives using an extensive panel data set of 45,517 futures prices and 233,104 option prices from January 2, 1990 until May 18, 2006, ensuring that the model provides a realistic description of the dynamics of the crude-oil market. This allows us to make not only qualitative, but also quantitative, predictions about the value of the expropriation option in various scenarios.

The expropriation option is an American-style option, since it can be exercised at any time during the life of the project. To value the option by simulation we use the Least Squares Monte Carlo (LSM) approach developed by Longstaff and Schwartz (2001). At every point in time, the government must compare the value of immediate exercise (expropriation) with the conditional expected value (under the risk neutral measure) from continuation. The conditional expected value of continuation, for each simulated path at each point in time, can be obtained from the fitted value of the linear regression of the discounted value (at the risk free rate) of the cash flows obtained from the simulation following the optimal exercise policy in the future, on a set of basis functions of the state variables. It is a recursive procedure starting from the maturity of the option and the outcome is the optimal exercise time for each path in the simulation. Knowing the optimal exercise time for each path, the expropriation option can then be easily valued. We can also estimate the value of the oil field to the government and to the firm both in the presence and absence of expropriation risk.

We find that, for a given contractual arrangement, the value of the expropriation option increases with the spot price, the slope of the futures curve and futures (and spot) price volatility. For a given set of state variables the value of the expropriation option decreases with the tax rate and with the various expropriation costs. Under realistic conditions, the value of the expropriation option is substantial and expropriation risk has a significant impact on the value of the oil field to the government and to the firm. We also find that if the government switches from corporate income taxes to royalty taxes in such a way that the value of the oil field to the government in the absence of expropriation risk is unchanged, the

\footnotetext{
${ }^{3}$ Alternatively, we could use one of the more parsimonious models in Schwartz (1997) to describe the dynamics of crude-oil spot and futures prices. However, none of these models incorporate stochastic volatility, making them inferior to the Trolle and Schwartz (2007) model in terms of pricing options. Furthermore, since we price the expropriation option by simulation, there are only minor computational advantages of using a more parsimonious model.

${ }^{4}$ New York Mercantile Exchange.
} 
value of the expropriation option increases. Finally, from the firm's point of view there is an "optimal" corporate income tax rate, that may be quite high in order to reduce the incentive for the government to expropriate.

With rational expectations, the firm will anticipate the situations under which the government expropriates. This implies that the increase in the oil field's value to the government due to expropriation risk is smaller than the decrease in the field's value to the firm, since oil may be extracted at a higher cost after the government expropriates and since there may be "reputational" costs to the government. In this sense, there is a "deadweight loss" associated with the possibility of expropriation. The reduction in the field's value to the firm due to expropriation risk is exactly matched by a reduction in the amount that the firm will be willing to bid during the process when the government auctions off the lease for the field. Hence, the total value that the government can extract from the field is smaller in the presence of expropriation risk than in the absence of expropriation risk. It would therefore be optimal for the government to commit itself to not expropriate the field, although such a commitment is not believable in countries without a credible legal framework to enforce contracts.

In our analysis, we will abstract from the various operational options that are typically imbedded in natural resource projects. These include options to adjust production as prices increase or decrease and the option to abandon the project if prices become too low. Due to the flexibility of the LSM approach, such options could be incorporated into the analysis. However, in the interest of parsimony, and because a wide variety of operational options have already been analyzed in the literature (see e.g. Brennan and Schwartz (1985) for an early paper), we do not include them here.

A couple of other papers also view expropriation risk through the lens of option pricing. These include Mahajan (1990) and Clark (2003) who both value an American-style expropriation option. However, in these papers the underlying models of uncertainty are highly stylized in order to obtain closed-form solutions for the expropriation option. ${ }^{5}$

\footnotetext{
${ }^{5}$ Our paper is also related to Rigobon's paper in this volume. In his model, the firm chooses the optimal production plan which, given the tax rates and the risk of expropriation, maximizes profits, while the government optimally chooses the royalty and income tax rates subject to certain restrictions. However, the commodity price process is highly simplified (a random walk) and he uses a simplified exercise strategy of the expropriation option (the government expropriates if profits rise above a fixed threshold). In contrast, in our model, the production plan and tax rates are exogenous. Instead we provide a realistic model for the evolution of commodity prices and compute the optimal exercise strategy of the expropriation option.
} 
The structure of the paper is as follows. Section 2 discusses the pricing of expropriation risk. Section 3 analyzes a stylized illustrative example. Section 4 concludes. Appendix A briefly describes the modelling of the crude-oil market. Appendix B describes the LSM procedure used for pricing the expropriation option.

\section{Pricing expropriation risk}

We assume that the oil field has a life of $T$ years. For the purpose of valuation we divide the $T$ years into $N$ periods, each with a length of $\Delta t=T / N$, and define $t_{n}=n \Delta t, n=0,1, \ldots, N$. We assume that oil produced during period $n$, i.e. from $t_{n-1}$ to $t_{n}$ is sold at the end of the period. The amount sold at time $t_{n}$ is denoted $Y\left(t_{n}\right)$.

Let $S\left(t_{i}\right)$ be the time- $t_{i}$ spot price of crude-oil and $F\left(t_{i}, t_{n}\right)$ be the time- $t_{i}$ price of a futures contract maturing at time $t_{n}$. The dynamics of $S\left(t_{i}\right)$ and $F\left(t_{i}, t_{n}\right)$ are given by the model proposed and estimated in Trolle and Schwartz (2007). For completeness, this model is summarized in Appendix A and estimates of its risk-neutral parameters are given in Table 1.

Let $r$ be the (constant) interest rate, $\tau_{\text {inc }}$ the corporate income tax rate, $\tau_{\text {roy }}$ the royalty tax rate and $C_{\text {firm }}$ and $C_{\text {gov }}$ the cost of producing one barrel of oil for the private firm and the state-run company, respectively. We assume that the private firm may produce oil more cost-efficiently than the state-run company, i.e. $C_{\text {firm }} \leq C_{\text {gov }}$, and that the government may pay a compensation to the firm, $K_{1}\left(t_{i}\right)$, and incur "reputational" costs, $K_{2}\left(t_{i}\right)$, if expropriating the oil field at time $t_{i}$.

Harrison and Kreps (1979), Harrison and Pliska (1981) and others have shown that absence of arbitrage implies the existence of a probability distribution such that securities are priced based on their discounted (at the risk free rate) expected cash flows, where the expectation is taken under this risk-neutral probability measure (also called the "equivalent martingale measure"). When futures contracts exist, futures prices are the expected spot prices at the maturities of the futures contracts under this risk-neutral measure.

If the government expropriates the oil field at time $t_{i}$ it will lose future tax receipts from the firm and may pay a compensation to the firm and incur "reputational" costs. This has a present value of

$V_{\text {cost }}\left(t_{i}\right)=\sum_{n=i+1}^{N} e^{-r\left(t_{n}-t_{i}\right)}\left[\left(F\left(t_{i}, t_{n}\right)\left(1-\tau_{\text {roy }}\right)-C_{\text {firm }}\right) \tau_{\text {inc }}+F\left(t_{i}, t_{n}\right) \tau_{\text {roy }}\right] Y\left(t_{n}\right)+K_{1}\left(t_{i}\right)+K_{2}\left(t_{i}\right)$.

Instead it will receive all future profits from the oil field, which may now have higher production 
costs, with a present value of

$$
V_{\text {gain }}\left(t_{i}\right)=\sum_{n=i+1}^{N} e^{-r\left(t_{n}-t_{i}\right)}\left(F\left(t_{i}, t_{n}\right)-C_{\text {gov }}\right) Y\left(t_{n}\right) .
$$

Let $\Pi\left(t_{i}\right)$ denote the (undiscounted) payoff from exercising the expropriation option at time $t_{i}$. It is given by

$$
\Pi\left(t_{i}\right)=\max \left(V_{\text {gain }}\left(t_{i}\right)-V_{\text {cost }}\left(t_{i}\right), 0\right) .
$$

The option is of the American type since it can be exercised at any time before the oil field has been depleted. In particular, we assume that it can be exercised at time $t_{n}, n=1, \ldots, N-1 .^{6}$ Let $P\left(t_{i}\right)$ denote the value of the option at time $t_{i}$, given that it has not already been exercised. At time $t_{N-1}$ the option value is simply

$$
P\left(t_{N-1}\right)=\Pi\left(t_{N-1}\right)
$$

At time $t_{i}, i=1, \ldots, N-2$ the value is given by

$$
\begin{aligned}
P\left(t_{i}\right) & =\max _{n=i, \ldots, N-1} E_{t_{i}}^{Q}\left[e^{-r\left(t_{n}-t_{i}\right)} \Pi\left(t_{n}\right)\right] \\
& =\max \left(\Pi\left(t_{i}\right), E_{t_{i}}^{Q}\left[e^{-r\left(t_{i+1}-t_{i}\right)} P\left(t_{i+1}\right)\right]\right) .
\end{aligned}
$$

In other words, prior to $t_{N-1}$ the option value is equal to the maximum of exercising the option immediately and the (risk-neutral) expected discounted value of keeping the option alive. This means that we can value the option by a backward iterative procedure starting with (4) to obtain $P\left(t_{N-1}\right)$, then applying (5) recursively to obtain $P\left(t_{N-2}\right), P\left(t_{N-3}\right)$ and so on until we reach $P\left(t_{1}\right)$. Then $P\left(t_{0}\right)=e^{-r\left(t_{1}-t_{0}\right)} P\left(t_{1}\right)$.

The main problem is how to compute the conditional expectation in (5). This is a nontrivial matter with a high-dimensional state vector such as the one used in this paper. A simple and powerful procedure for pricing American options was suggested by Longstaff and Schwartz (2001). It is a simulation-based procedure called Least Squares Monte Carlo. We describe the procedure in more detail in Appendix B. It yields an estimate of the option price as well as an estimate of the optimal exercise strategy.

Suppose we simulate $M$ paths. ${ }^{7}$ Let $t_{Z_{m}}$ denote the estimated time of expropriation along path $m$ (with $Z_{m}=N$ if no expropriation takes place) and $S_{m}\left(t_{n}\right)$ the spot price at time $t_{n}$

${ }^{6}$ We exclude current time $t_{0}$ from the set of exercise opportunities. We also exclude $t_{N}$ since at that time the oil field has been depleted.

${ }^{7}$ Throughout the paper, we use 10.000 paths and antithetic variates in the simulations. 
along path $m$. Then, the value of the oil field to the firm in the presence of expropriation risk is

$$
\begin{aligned}
V_{\text {firm }}^{\text {exp }}\left(t_{0}\right)= & \frac{1}{M} \sum_{m=1}^{M}\left(\sum_{n=1}^{Z_{m}} e^{-r\left(t_{n}-t_{0}\right)}\left(S_{m}\left(t_{n}\right)\left(1-\tau_{\text {roy }}\right)-C_{\text {firm }}\right)\left(1-\tau_{\text {inc }}\right) Y\left(t_{n}\right)\right. \\
& \left.+e^{-r\left(t_{Z_{m}}-t_{0}\right)} K_{1}\left(t_{Z_{m}}\right)\right)
\end{aligned}
$$

while the value of the oil field to the government is

$$
\begin{aligned}
V_{\text {gov }}^{\text {exp }}\left(t_{0}\right)= & \frac{1}{M} \sum_{m=1}^{M}\left(\sum_{n=1}^{Z_{m}} e^{-r\left(t_{n}-t_{0}\right)}\left[\left(S_{m}\left(t_{n}\right)\left(1-\tau_{\text {roy }}\right)-C_{\text {firm }}\right) \tau_{\text {inc }}+S_{m}\left(t_{n}\right) \tau_{\text {roy }}\right] Y\left(t_{n}\right)\right. \\
& \left.-e^{-r\left(t_{Z_{m}}-t_{0}\right)}\left(K_{1}\left(t_{Z_{m}}\right)+K_{2}\left(t_{Z_{m}}\right)\right)+\sum_{n=Z_{m}+1}^{N} e^{-r\left(t_{n}-t_{0}\right)}\left(S_{m}\left(t_{n}\right)-C_{\text {gov }}\right) Y\left(t_{n}\right)\right)
\end{aligned}
$$

In the absence of expropriation risk, the value of the oil field to the firm and to the government are given analytically. The value to the firm is

$$
V_{\text {firm }}\left(t_{0}\right)=\sum_{n=1}^{N} e^{-r\left(t_{n}-t_{0}\right)}\left(F\left(t_{0}, t_{n}\right)\left(1-\tau_{\text {roy }}\right)-C_{\text {firm }}\right)\left(1-\tau_{\text {inc }}\right) Y\left(t_{n}\right),
$$

while the value to the government is 8

$$
V_{\text {gov }}\left(t_{0}\right)=\sum_{n=1}^{N} e^{-r\left(t_{n}-t_{0}\right)}\left[\left(F\left(t_{0}, t_{n}\right)\left(1-\tau_{\text {roy }}\right)-C_{\text {firm }}\right) \tau_{\text {inc }}+F\left(t_{0}, t_{n}\right) \tau_{\text {roy }}\right] Y\left(t_{n}\right) .
$$

\section{Illustrative example}

\subsection{The base-line parameters}

We consider a medium-sized oil field with an annual production of 10 million barrels for ten years. In the base-line case, we make the following assumptions: In case of expropriation, the government incurs "reputational" costs of 1.0 billion USD and pays the firm a compensation of 50 million USD times the remaining life of the oil field measured in years. ${ }^{9}$ Furthermore, the private firm has a production cost of $10 \mathrm{USD} / \mathrm{bl}$, while the state-run company has a production

\footnotetext{
${ }^{8}$ Note that we may alternatively compute the value of the oil field to the government in the presence of expropriation risk as the value in the absence of expropriation risk plus the value of the expropriation option, i.e. $V_{\text {gov }}^{\text {exp }}\left(t_{0}\right)=V_{\text {gov }}\left(t_{0}\right)+P\left(t_{0}\right)$.

${ }^{9}$ For instance, if the government expropriates the oil field after seven years the firm will receive a compensation of 150 million USD.
} 
cost of $15 \mathrm{USD} / \mathrm{bl}$, the corporate income tax rate is 60 percent and the royalty tax rate is zero. ${ }^{10}$ The sensitivity of the results to these assumptions will be examined later. Finally, we assume an interest rate of 5 percent and that expropriation can take place monthly. In the notation of Section 2 we have $T=10, N=120, Y\left(t_{i}\right)=\Delta t \times 10$ million bls, $K_{1}\left(t_{i}\right)=\left(T-t_{i}\right) \times 50$ million USD, $K_{2}\left(t_{i}\right)=1000$ million USD, $C_{\text {firm }}=10 \mathrm{USD} / \mathrm{bl}, C_{\text {gov }}=15 \mathrm{USD} / \mathrm{bl}, \tau_{\text {inc }}=0.60$, $\tau_{\text {roy }}=0$ and $r=0.05$.

In the following, we will focus on four statistics: 1) The dollar value of the expropriation option, i.e. $P\left(t_{0}\right)$. 2) The "deadweight loss" associated with the possibility of expropriation, i.e. $\left(V_{\text {gov }}\left(t_{0}\right)+V_{\text {firm }}\left(t_{0}\right)\right)-\left(V_{\text {gov }}^{\text {exp }}\left(t_{0}\right)+V_{\text {firm }}^{\text {exp }}\left(t_{0}\right)\right)$. The "deadweight loss" is due to the "reputational" costs and the fact that oil is extracted at a higher cost after the government expropriates. This implies that the increase in the oil field's value to the government because of expropriation risk is always smaller than the decrease in the oil field's value to the firm. 3) The percentage increase in the oil field's value to the government when taking into account the expropriation possibility, i.e. $V_{\text {gov }}^{\text {exp }}\left(t_{0}\right) / V_{\text {gov }}\left(t_{0}\right)-1$. 4) The percentage decrease in the oil field's value to the firm when taking into account the expropriation possibility, i.e. $-\left(V_{\text {firm }}^{\text {exp }}\left(t_{0}\right) / V_{\text {firm }}\left(t_{0}\right)-1\right)$.

\subsection{Results}

\subsubsection{Expropriation risk as a function of state variables}

We first investigate how these key statistics depend on the state variables. Figure 1 shows the state variables over the period January 2, 1990 to May 18, 2006 as estimated by Trolle and Schwartz (2007). $S(t)$ is the spot price, $x(t)$ determines the slope of the futures curve through the cost of carry, $v(t)$ determines futures (and spot) price volatility and $\phi(t)$ is a locally deterministic state variable that enables the dynamics of the futures curve to be described by a Markov process.

We first vary $S(t)$ and $x(t)$, holding $v(t)$ constant at its long-run mean of 2.79 over the sample. Based on Figure 1, a realistic range for $S(t)$ is $20 \mathrm{USD} / \mathrm{bl}$ to $80 \mathrm{USD} / \mathrm{bl}^{11}$ while a realistic range for $x(t)$ is -3 to 3 . To give a sense of how $S(t)$ and $x(t)$ impacts the futures

\footnotetext{
${ }^{10}$ For simplicity, we assume that production, production costs and tax rates are constant throughout the life of the oil field. However, these could easily be made time and state dependent. For instance, it is likely that annual production decreases and the marginal production cost increases as the oil field gets depleted.

${ }^{11}$ However, after the end of our sample period, crude-oil trading on NYMEX reached 100 USD/bl.
} 
curve, Figure 2 shows the futures curve at four extreme combinations of $S(t)$ and $x(t)$ : $\mathrm{USD} / \mathrm{bl},-3),(20 \mathrm{USD} / \mathrm{bl}, 3),(80 \mathrm{USD} / \mathrm{bl},-3)$ and (80 USD/bl, 3). Clearly, the futures curve is strongly in backwardation when $x(t)=-3$, while the futures curve is strongly in contango when $x(t)=3$. Since the correlation between innovations to $S(t)$ and $x(t)$ is strongly negative (the estimate of $\rho_{12}$ is -0.88 in Table 1 ) it is most likely that $x(t)$ decreases as $S(t)$ increases. That is, the futures curve is most likely to be in contango when the spot price is low and in backwardation when the spot price is high.

Figure 3 shows how the key statistics depend on $S(t)$ and $x(t)$. Not surprisingly, the dollar value of the expropriation option, the "deadweight loss", and the increase (decrease) of the oil field's value to the government (firm) all rise with $S(t)$ and $x(t)$. When the spot price is low there is little incentive to expropriate given the various expropriation costs. The incentive is even smaller if the futures curve is in backwardation, since in that case spot prices are expected (under the risk-neutral measure) to decrease in the future. In contrast, when the spot price is high and the futures curve is in contango, the incentive to expropriate is higher since the prospect of receiving all the profits rather than a fraction of the profits may dominate the expropriation costs. For high spot prices and upward-sloping futures curves, the value of the expropriation option and the "deadweight loss" are very large. Keep in mind, though, that a scenario where the futures curve is strongly in contango at high spot prices is not very likely given the historical dynamics.

To give a sense of expropriation risk under reasonable market conditions we analyze the following three specific dates in the sample: October 11, 1990, December 21, 1998 and April 21, 2006 (in Figure 1 these dates are marked by vertical grey lines). The first date is the date when the spot price reaches its maximum during the first Gulf War and also corresponds to the date where $x(t)$ attains its minimum during the sample period. The second date is the date when the spot price reaches its minimum and $x(t)$ reaches its maximum during the sample period. These two dates clearly illustrates the inverse relationship that normally exist between the spot price and the slope of the futures curve. The last date corresponds to the date when the spot price reaches its maximum during the sample period. Note that the futures curve is not strongly backwardated at this date reflecting the fact that the slope of the futures curve also exhibits variation that is independent of the spot price. Table 2 shows the values of the state variables and a number of statistics related to the possibility of expropriation on these three dates. On the first two dates, the value of the expropriation option and the "deadweight loss" are very small. On the third date, however, expropriation risk is high. The value of 
the expropriation option is 159 million USD and the valuation of the oil field is significantly affected. $^{12}$ The value of the field to the firm (government) is 1978 (2966) million USD in the absence of expropriation risk compared with 993 (3125) million USD in the presence of expropriation risk. For the firm, this is a decrease in value of almost 50 percent. There is also a very large "deadweight loss" of 825 million USD.

We next vary $S(t)$ and $v(t)$, holding $x(t)$ constant at zero (corresponding to a slightly upward-sloping futures curve). Figure 1 shows that $v(t)$ reached almost 20 at the beginning of "Operation Desert Storm" in 1991 - a time of extreme market stress. Therefore, we vary $v(t)$ between 0 and 20. Figure 4 shows how the key statistics depend $S(t)$ and $v(t)$. Consistent with standard option pricing theory, the dollar value of the expropriation option, and therefore the increase in the oil field's value to the government, rise with volatility. However, the oil field's value to the firm and the "deadweight loss" are not necessarily increasing in volatility. In fact, for high spot prices they are decreasing in volatility since the likelihood of expropriation may decrease.

\subsubsection{Expropriation risk as a function of tax rate and expropriation costs}

We now investigate how, for a given set of state variables, the statistics depend on the tax rate and the expropriation costs. ${ }^{13}$ Figure 5 shows how the key statistics depend on $\tau_{\text {inc }}$ and $K_{2}$, when we vary $\tau_{i n c}$ between zero and 100 percent and $K_{2}$ between zero and 2000 million USD. The dollar value of the expropriation option and the increase (decrease) of the oil field's value to the government (firm) all decline with $\tau_{i n c}$ and $K_{2}$. When the tax rate is 100 percent, the government never expropriates, since it receives all profits from the oil field. In contrast, for low tax rates and low "reputational" costs, the government almost certainly expropriates. In these instances, the value of the expropriation option may easily exceed one billion USD.

For a given $K_{2}$, the "deadweight loss" decreases with $\tau_{\text {inc }}$ since the expropriation likelihood decreases with $\tau_{\text {inc }}$. However, for a given $\tau_{\text {inc }}$, the "deadweight loss" as a function of $K_{2}$ is "humped-shaped". The reason is that there are two opposing forces: although the expropriation likelihood decreases with $K_{2}$, the inefficiency is greater when expropriation occurs. For low tax rates and high (although not extreme) "reputational" costs, the "deadweight loss" may also exceed one billion USD.

\footnotetext{
${ }^{12}$ The risk-neutral likelihood that the field will get expropriated during its 10 year lifespan is 62 percent.

${ }^{13}$ In the rest of the paper, unless otherwise noticed, the state variables are given by $S(t)=50, x(t)=0$ and $v(t)=2.79$.
} 
Figure 6 shows how the key statistics depend on $K_{2}$ and $C_{\text {gov }}$, when we vary $K_{2}$ between zero and 2000 million USD and $C_{\text {gov }}$ between $10 \mathrm{USD} / \mathrm{bl}$ (i.e. equal to $C_{\text {firm }}$ ) and $20 \mathrm{USD} / \mathrm{bl}$. Except for the "deadweight loss", Figure 6 is qualitatively similar to Figure 5. However, the "deadweight loss" now exhibits a "hump-shape" along both dimensions. When $K_{2}=0$ and $C_{\text {gov }}=10 \mathrm{USD} / \mathrm{bl}$, the government almost certainly expropriates, but there is no inefficiency. As $K_{2}$ and/or $C_{\text {gov }}$ increase, the expropriation likelihood decreases, but the inefficiency, when expropriation does occur, increases.

\subsubsection{Royalties vs. corporate income taxes}

We now investigate how the choice between royalty tax and corporate income tax affects the value of the expropriation option. So far we have assumed that the government relies exclusively on corporate income taxes. We now compare this with the opposite case where the government relies exclusively on royalties. We do this for the same combinations of $S(t)$ and $x(t)$ as in Figure 3. In the baseline case we had $\tau_{i n c}=0.60$ and $\tau_{\text {roy }}=0$. Here, we first set $\tau_{\text {inc }}=0$ and compute the $\tau_{\text {roy }}$ which, in the absence of expropriation risk, gives the same value of the oil field to the government. Next, we compute the value of the expropriation option with this $\tau_{\text {roy }}$.

Panel A of Figure 7 shows $\tau_{\text {roy }}$ while Panel B shows $P_{\text {roy }}\left(t_{0}\right)-P_{\text {inc }}\left(t_{0}\right)$, where $P_{\text {roy }}\left(t_{0}\right)$ and $P_{i n c}\left(t_{0}\right)$ denote the values of the expropriation option when the government relies exclusively on royalties and corporate income taxes, respectively. The value of the expropriation option is always larger with royalties than with corporate income taxes. The reason is that the royalty tax rate is always lower than the corporate income tax rate of 60 percent which implies that for high oil prices the revenues from royalties are lower than from corporate income taxes making expropriation more profitable. The differences in the value of the expropriation option are largest for combinations of state variables where there is some probability of expropriation. The differences are low when $S(t)$ and $x(t)$ are both low or when $S(t)$ and $x(t)$ are both high. In the former case, the government never expropriates, while in the latter case, the government almost surely expropriates regardless of whether it relies on royalties or corporate income taxes. 


\subsubsection{The "optimal" tax rate for the firm}

In the absence of expropriation risk, it is optimal for the firm to negotiate the most favorable terms under which to exploit the oil field. In our case, this means obtaining the lowest possible tax rate. However, in the presence of expropriation risk, the firm must take into account that the incentive to expropriate is higher for lower tax rates. For simplicity, we return to the case where the government relies exclusively on corporate income taxes. Figure 8 shows the oil field's value to the firm as a function of $\tau_{i n c}$ and $K_{2}$. For low values of $K_{2}$ the "optimal" tax rate that maximizes the project's value to the firm is quite high around 70 percent. As $K_{2}$ increases, the "optimal" tax rate decreases, since the incentive to expropriate decreases.

\subsubsection{Who bears the "deadweight loss"}

Suppose $t_{0}$ is the time when the government auctions off the lease for the oil field. Furthermore, assume that extraction requires an initial investment of $I$. In the absence of expropriation risk, a firm would be willing to pay up to $V_{\text {firm }}\left(t_{0}\right)-I$ for the lease, while in the presence of expropriation risk, it would only be willing to pay up to $V_{\text {firm }}^{\text {exp }}\left(t_{0}\right)-I{ }^{14}$ If the government could commit itself, ex-ante, not to expropriate, it would be able to extract a value of up to $V_{\text {gov }}\left(t_{0}\right)+V_{\text {firm }}\left(t_{0}\right)-I$ from the oil field. However, in the absence of a legal framework to enforce contracts, such a commitment is not credible, since, ex-post, after the firm has paid for the lease and made the initial investment, it will be optimal for the government to renege on its promise in some states of the world. A rational firm will anticipate this behavior and the maximum value that the government can extract from the field will be $V_{\text {gov }}^{\text {exp }}\left(t_{0}\right)+V_{\text {firm }}^{\text {exp }}\left(t_{0}\right)-I$. Ultimately, therefore, it is the government that bears the "deadweight loss" associated with the possibility of expropriation.

\subsection{Implementation}

When implementing the model for actual valuation, the analyst must choose a set of reasonable parameters. The parameters and state variables of the Trolle and Schwartz (2007) model can be obtained by calibrating the model to, say, NYMEX futures and options prices. ${ }^{15}$ Tax rates

\footnotetext{
${ }^{14}$ For simplicity, we abstract from the option to defer the initial investment.

${ }^{15}$ The price of crude-oil from a particular oil field will usually differ from the price at NYMEX (which refers to the benchmark West Texas Intermediate blend) due to differences in quality. However, the correlation with the NYMEX price is likely to be very high which implies that one can calibrate the model to NYMEX derivatives
} 
are given and reserve size and production can be estimated. The main problem is estimating the government's expropriation costs. While it may be possible to infer production costs for a state-run oil company, it is harder to estimate the compensation to the firm in case of expropriation and even more difficult to estimate the "reputational" costs. Figure 5 and 6 show that the results are sensitive to these costs and any conclusions drawn from the model should reflect this uncertainty.

\section{Conclusion}

In this paper we develop a model for pricing expropriation risk in natural resource projects in general and an oil field in particular. The government is viewed as holding an American-style option to expropriate the oil field. Expropriation is not costless, however, and we consider three possible expropriation costs for the government: A state-run company may produce oil less cost-efficiently than a private firm, the government may have to pay a compensation to the firm and, perhaps most importantly, there may be "reputational" costs as investors will lose confidence in the government's willingness to honor contracts. The dynamics of key variables - the spot price, futures prices and volatility - is described by a model proposed and estimated in Trolle and Schwartz (2007) and the expropriation option is valued by simulations using the LSM approach developed by Longstaff and Schwartz (2001).

We find that the value of the expropriation option increases with the spot price, the slope of the futures curve and futures (and spot) price volatility, while it decreases with the corporate income tax rate and the various expropriation costs. For reasonable parameter values and under market conditions not too different from what has been seen in recent years, the value of the expropriation option can be substantial. The value of the expropriation option increases if the government switches from corporate income taxes to royalty taxes in such a way that the value of the oil field to the government in the absence of expropriation risk is unchanged. In order to reduce the incentive for the government to expropriate, from the firm's point of view there is an "optimal" tax rate on corporate profits which may be quite high. Furthermore, when firms act rationally, the possibility of expropriation leads to a decrease in the total value that the government can initially extract from the oil field.

To keep the analysis focused, we have assumed an exogenous production process. ${ }^{16}$ An and subsequently adjust the spot price to reflect the actual crude-oil quality.

${ }^{16}$ In our example, production is constant. However, it is straightforward to make production time and state 
interesting extension of the model would be to make production endogenous and take into account the various operational options that are typically imbedded in natural resource projects. This should be feasible, given the flexibility of the LSM approach.

Furthermore, although we have discussed royalties vs. corporate income taxes, the tax structure remains very simple. It would be interesting to study the optimal resource extraction contract within our setup, perhaps drawing on some of the results in Engel and Fishers' paper in this volume.

dependent. 


\section{Appendices}

\section{Appendix A: The Trolle and Schwartz (2007) model}

Here, we briefly review the model of Trolle and Schwartz (2007). ${ }^{17}$ The model is based on the Heath, Jarrow, and Morton (1992) framework for interest rate dynamics and takes the initial futures curve or, equivalently, the initial cost of carry curve as given. $S(t)$ denotes the time- $t$ spot price of the commodity, $\delta(t)$ denotes the time- $t$ instantaneous spot cost of carry, $y(t, T)$ denote the time- $t$ instantaneous forward cost of carry at time $T$ and $v(t)$ denotes the volatility state variable. The general specification of the model is given by

$$
\begin{aligned}
\frac{d S(t)}{S(t)} & =\delta(t) d t+\sigma_{S} \sqrt{v(t)} d W_{1}^{Q}(t) \\
d y(t, T) & =\mu_{y}(t, T) d t+\sigma_{y}(t, T) \sqrt{v(t)} d W_{2}^{Q}(t) \\
d v(t) & =\kappa_{v}(\theta-v(t)) d t+\sigma_{v} \sqrt{v(t)} d W_{3}^{Q}(t),
\end{aligned}
$$

where $W_{1}^{Q}(t), W_{2}^{Q}(t)$ and $W_{3}^{Q}(t)$ denote correlated Wiener processes under the risk-neutral measure with pairwise correlations given by $\rho_{12}, \rho_{13}$ and $\rho_{123}$, and the drift term in (11) is given by

$$
\mu_{y}(t, T)=-v(t) \sigma_{y}(t, T)\left(\rho_{12} \sigma_{S}+\int_{t}^{T} \sigma_{y}(t, u) d u\right)
$$

to ensure that the model is arbitrage-free.

We obtain a highly tractable model by specifying $\sigma_{y}(t, T)$ as

$$
\sigma_{y}(t, T)=\alpha e^{-\gamma(T-t)} .
$$

In this case futures prices are exponentially affine in three state variables $s(t) \equiv \log (S(t)), x(t)$ and $\phi(t)$ which, along with $v(t)$ jointly constitute an affine state vector. In general, the model is time-inhomogeneous but we obtain a time-homogeneous model by assuming that the initial forward cost of carry curve, $y(0, t)$, is flat and equal to a constant, $\varphi$. Let $F(t, T)$ denote the time- $t$ price of a futures contract maturing at time $T$. Then we have

$$
F(t, T)=\exp \left\{\varphi(T-t)+s(t)+\frac{\alpha}{\gamma}\left(1-e^{-\gamma(T-t)}\right) x(t)+\frac{\alpha}{2 \gamma}\left(1-e^{-2 \gamma(T-t)}\right) \phi(t)\right\},
$$

\footnotetext{
${ }^{17}$ In fact, in that paper we propose two models, one model with one volatility factor and another model with two volatility factors. We show that the latter model outperforms the former, particularly in terms of pricing short-term derivatives. However, for pricing real options with long maturities, the performance of the models are likely to be similar. In the interest of parsimony, we therefore work with the model with one volatility factor.
} 
where $s(t), x(t)$ and $\phi(t)$ evolve according to

$$
\begin{aligned}
d s(t) & =\left(\varphi+\alpha x(t)+\alpha \phi(t)-\frac{1}{2} \sigma_{S}^{2} v(t)\right) d t+\sigma_{S} \sqrt{v(t)} d W_{1}^{Q}(t) \\
d x(t) & =\left(-\gamma x(t)-\left(\frac{\alpha}{\gamma}+\rho_{12} \sigma_{S}\right) v(t)\right) d t+\sqrt{v(t)} d W_{2}^{Q}(t) \\
d \phi(t) & =\left(\frac{\alpha}{\gamma} v(t)-2 \gamma \phi(t)\right) d t .
\end{aligned}
$$

\section{Appendix B: Pricing the expropriation option by the LSM algorithm}

Here we briefly explain how to price the expropriation option using the LSM algorithm of Longstaff and Schwartz (2001).

1. Simulate $M$ paths of $X_{t}$. Let $X_{m}\left(t_{i}\right), \widehat{P}_{m}\left(t_{i}\right)$ and $\Pi_{m}\left(t_{i}\right)$ denote the value of the state vector, the estimated option value and the option payoff, respectively, at time $t_{i}$ along the $m$ 'th path. Furthermore, let $\mathcal{I}_{i}$ denote the subset of paths for which the option is in-the-money at time $t_{i}$

2. At time $t_{N-1}$ the value of the option is equal to its immediate exercise value. Therefore, $\widehat{P}_{m}\left(t_{N-1}\right)=\Pi_{m}\left(t_{N-1}\right), m=1, \ldots, M$.

3. Apply backwards induction from $i=N-2$ to $i=1$.

- At time $t_{i}$ the value of the option is equal to the maximum of its immediate exercise value and its expected continuation value. Longstaff and Schwartz (2001) suggest approximating the expected continuation value by the fitted value of a cross-sectional least squares regression where the ex-post realized cash-flows from continuation are regressed on a set of basis functions of the state variables. In other words, we run the regression

$$
e^{-r\left(t_{i+1}-t_{i}\right)} \widehat{P}_{m}\left(t_{i+1}\right)=\sum_{j=1}^{J} \beta_{j} \psi_{j}\left(X_{m}\left(t_{i}\right)\right)+\epsilon_{m}, m \in \mathcal{I}_{i}
$$

where $\psi_{j}$ denotes the $j^{\prime}$ th basis function. ${ }^{18}$ Note that we only use the paths for which the option is in-the-money at time $t_{i}$ since it is only on these paths that the government

\footnotetext{
${ }^{18}$ We use the following set of functions: $1, s_{m}\left(t_{i}\right), s_{m}\left(t_{i}\right)^{2}, x_{m}\left(t_{i}\right), x_{m}\left(t_{i}\right)^{2}, v_{m}\left(t_{i}\right), v_{m}\left(t_{i}\right)^{2}, s_{m}\left(t_{i}\right) x_{m}\left(t_{i}\right)$, $s_{m}\left(t_{i}\right) v_{m}\left(t_{i}\right)$ and $x_{m}\left(t_{i}\right) v_{m}\left(t_{i}\right)$. Adding higher-order terms does not change the results.
} 
may choose to exercise. The fitted value of this regression

$$
\widehat{C}_{m}\left(t_{i}\right)=\sum_{j=1}^{J} \widehat{\beta}_{j} \psi_{j}\left(X_{m}\left(t_{i}\right)\right), m \in \mathcal{I}_{i}
$$

is an efficient unbiased estimate of the expected continuation value.

- Update the estimated option value along each path as:

$$
\widehat{P}_{m}\left(t_{i}\right)= \begin{cases}\Pi_{m}\left(t_{i}\right), & \Pi_{m}\left(t_{i}\right) \geq \widehat{C}_{m}\left(t_{i}\right) \\ e^{-r\left(t_{i+1}-t_{i}\right)} \widehat{P}_{m}\left(t_{i+1}\right), & \Pi_{m}\left(t_{i}\right)<\widehat{C}_{m}\left(t_{i}\right),\end{cases}
$$

for $m \in \mathcal{I}_{i}$ and

$$
\widehat{P}_{m}\left(t_{i}\right)=e^{-r\left(t_{i+1}-t_{i}\right)} \widehat{P}_{m}\left(t_{i+1}\right)
$$

for $m \notin \mathcal{I}_{i}$.

4. Compute the estimated option value as

$$
\widehat{P}\left(t_{0}\right)=e^{-r\left(t_{1}-t_{0}\right)} \frac{1}{M} \sum_{m=1}^{M} \widehat{P}_{m}\left(t_{1}\right) .
$$

In general, we obtain a lower bound on the option value, since we approximate the continuation value. Clément, Lamberton, and Protter (2002) prove that the LSM algorithm converges to the true option price as $M \rightarrow \infty$.

As part of the LSM algorithm we also obtain the early exercise strategy. Let $t_{Z_{m}}$ denote the estimated time of expropriation along path $m$. We start by setting $Z_{m}=N$ for $m=1, \ldots, M$. corresponding to no expropriation along any of the paths. Then we move backwards from $i=N-1$ to $i=1$. If at time $t_{i}$ along path $m$ it is optimal to exercise the option we set $Z_{m}=i$. 


\begin{tabular}{lcc}
\hline & estimate & standard error \\
\hline$\kappa_{v}$ & 1.0125 & 0.0123 \\
$\sigma_{v}$ & 2.8226 & 0.0212 \\
$\alpha$ & 0.1365 & 0.0024 \\
$\gamma$ & 0.7796 & 0.0011 \\
$\sigma_{S}$ & 0.2275 & 0.0017 \\
$\rho_{12}$ & -0.8797 & 0.0040 \\
$\rho_{13}$ & -0.0912 & 0.0018 \\
$\rho_{23}$ & -0.1128 & 0.0116 \\
$\varphi$ & 0.0054 & 0.0001 \\
\hline
\end{tabular}

Notes: The table shows maximum-likelihood estimates of the model in Appendix A based on daily data. For details we refer to Trolle and Schwartz (2007). This table is an excerpt from their Table 5.

Table 1: Parameter estimates 


\begin{tabular}{lccc}
\hline & Oct. 11, 1990 & Dec. 21, 1998 & Apr. 21, 2006 \\
\hline$S\left(t_{0}\right)$ & 41.26 & 10.62 & 78.03 \\
$x\left(t_{0}\right)$ & -4.67 & 2.49 & -0.78 \\
$\phi\left(t_{0}\right)$ & 0.29 & 0.33 & 0.33 \\
$v\left(t_{0}\right)$ & 13.72 & 7.11 & 2.17 \\
$P\left(t_{0}\right)$, million USD & 0.55 & 0.05 & 159.18 \\
$V_{\text {gov }}\left(t_{0}\right)$, million USD & 557.45 & 296.74 & 2966.30 \\
$V_{\text {gov }}^{\text {exp }}\left(t_{0}\right)$, million USD & 558.00 & 296.78 & 3125.49 \\
$V_{\text {gov }}^{\text {exp }}\left(t_{0}\right) / V_{\text {gov }}\left(t_{0}\right)-1, \%$ & 0.10 & 0.02 & 5.37 \\
$V_{\text {firm }}\left(t_{0}\right)$, million USD & 371.63 & 197.82 & 1977.53 \\
$V_{\text {firm }}^{\text {exp }}\left(t_{0}\right)$, million USD & 370.66 & 197.64 & 993.06 \\
$V_{\text {firm }}^{\text {exp }}\left(t_{0}\right) / V_{\text {firm }}\left(t_{0}\right)-1, \%$ & -0.26 & -0.09 & -49.78 \\
"Deadweight loss", million USD & 0.42 & 0.14 & 825.29 \\
\hline
\end{tabular}

Notes: The table shows, on three specific dates, the values of the state variables, the value of the expropriation option $\left(P\left(t_{0}\right)\right)$, the oil field's value to the government without and with expropriation possibility and the percentage change in value $\left(V_{\text {gov }}\left(t_{0}\right), V_{\text {gov }}^{\text {exp }}\left(t_{0}\right)\right.$ and $V_{\text {gov }}^{\text {exp }}\left(t_{0}\right) / V_{\text {gov }}\left(t_{0}\right)-1$, respectively), the oil field's value to the firm without and with expropriation possibility and the percentage change in value $\left(V_{\text {firm }}\left(t_{0}\right), V_{\text {firm }}^{\text {exp }}\left(t_{0}\right)\right.$ and $V_{\text {firm }}^{\text {exp }}\left(t_{0}\right) / V_{\text {firm }}\left(t_{0}\right)-1$, respectively), and the "deadweight loss", i.e. $\left(V_{\text {gov }}\left(t_{0}\right)+V_{\text {firm }}\left(t_{0}\right)\right)-\left(V_{\text {gov }}^{\text {exp }}\left(t_{0}\right)+V_{\text {firm }}^{\text {exp }}\left(t_{0}\right)\right)$.

Table 2: Expropriation risk on three specific dates 

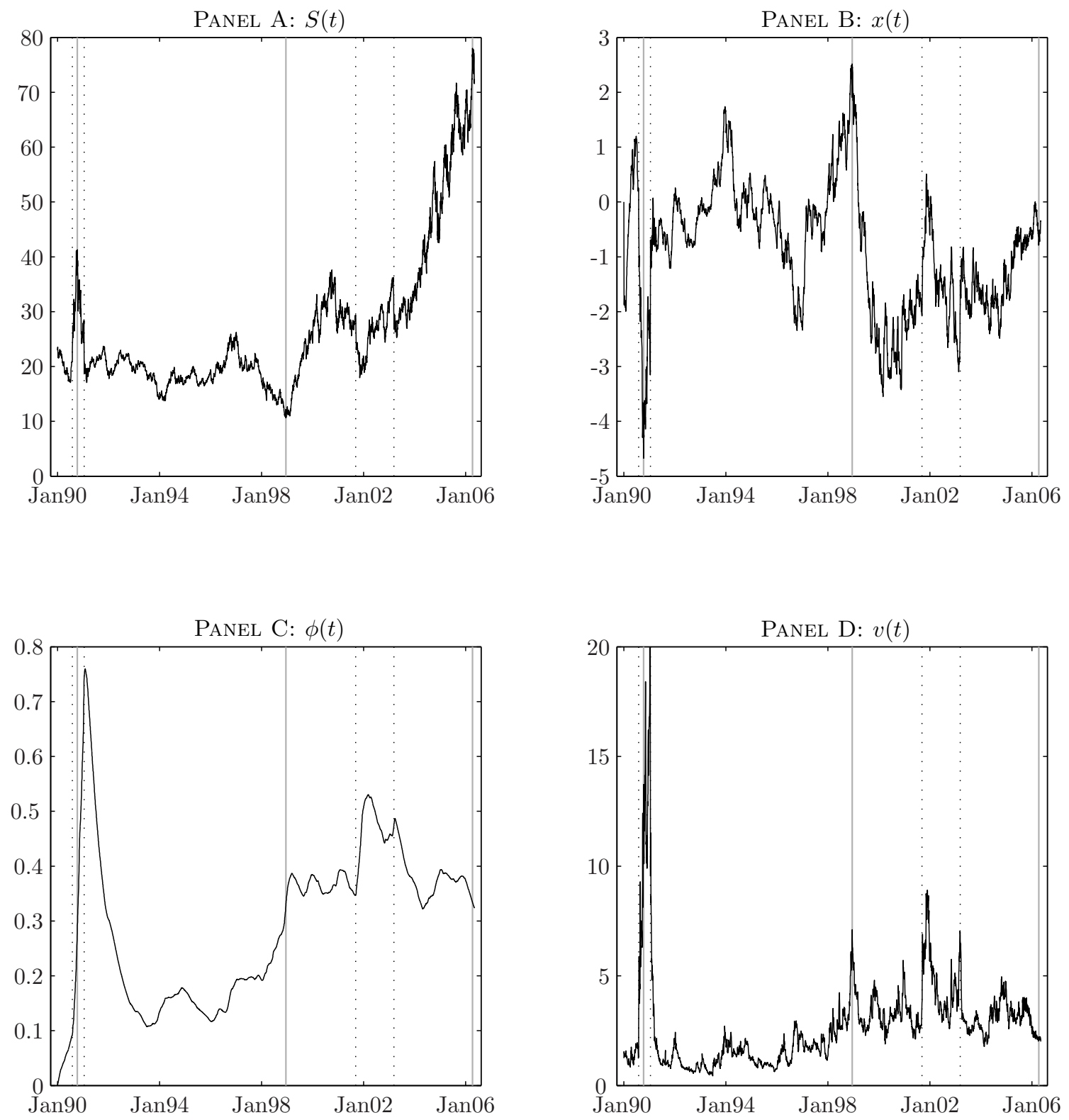

Figure 1: Time series of state variables

The figure shows time series of the state variables as estimated by Trolle and Schwartz (2007). This figure is an excerpt from their Figure 5. The vertical dotted lines mark the Iraqi invasion of Kuwait on August 2, 1990, the beginning of the US-led liberation of Kuwait ("Operation Desert Storm") on January 17, 1991, the September 11, 2001 terrorist attacks and the US-led invasion of Iraq on March 20, 2003, respectively. The vertical grey lines mark the three dates that we investigate further in Table 2: October 11, 1990, December 21, 1998 and April 21, 2006. Each time series consists of 4082 daily observations from January 2, 1990 to May 18, 2006. 


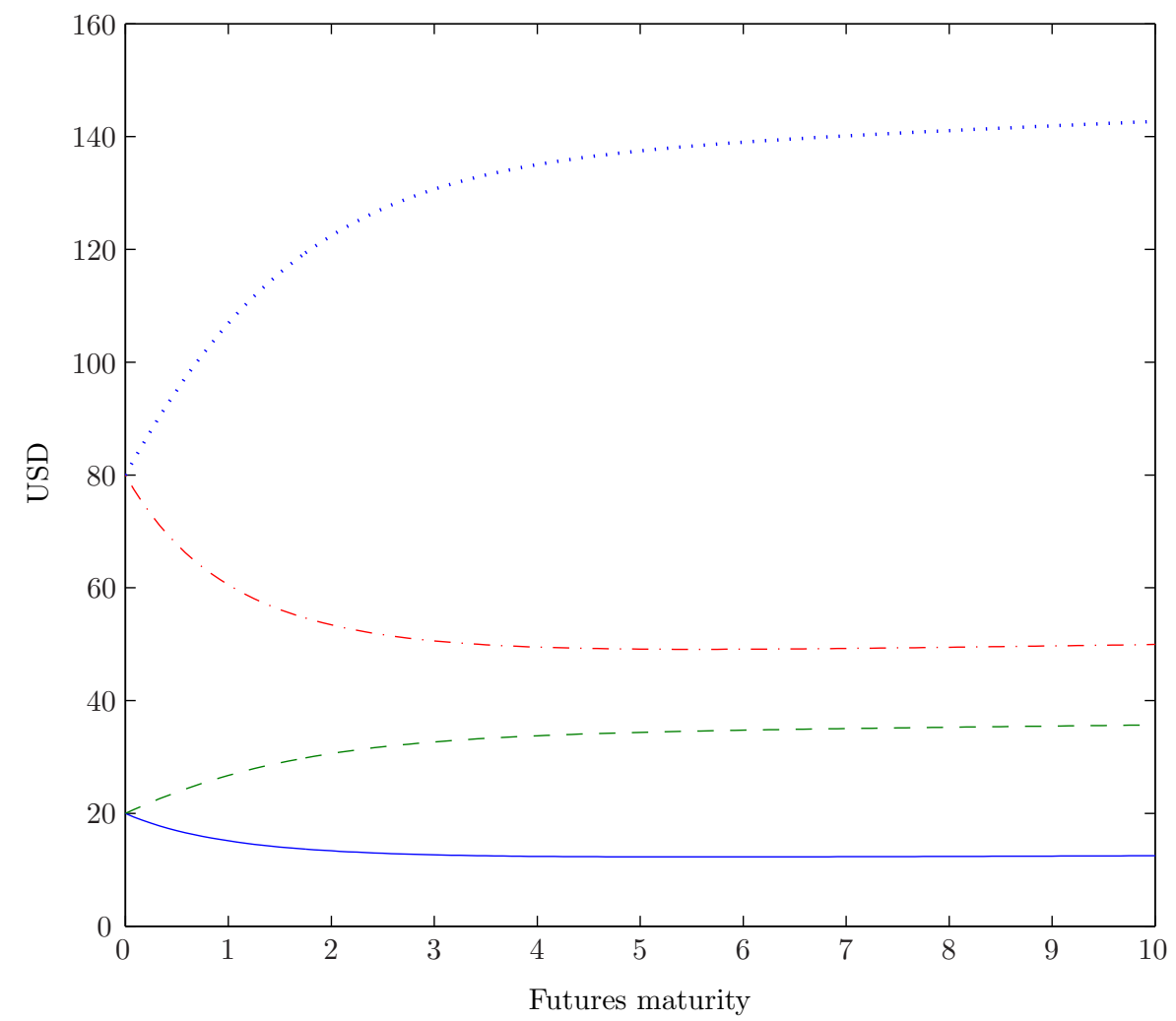

Figure 2: Futures curves

The figure shows the futures curves for different combinations of $S(t)$ and $x(t)$. ' $\longrightarrow$ ' corresponds to $S(t)=20$ and $x(t)=-3,{ }^{\prime}-{ }^{-}$' corresponds to $S(t)=20$ and $x(t)=3,{ }^{\prime}-{ }^{-}{ }^{\prime}$ ' corresponds to $S(t)=80$ and $x(t)=-3$, and '.....' corresponds to $S(t)=80$ and $x(t)=3$. 
Panel A: Option value

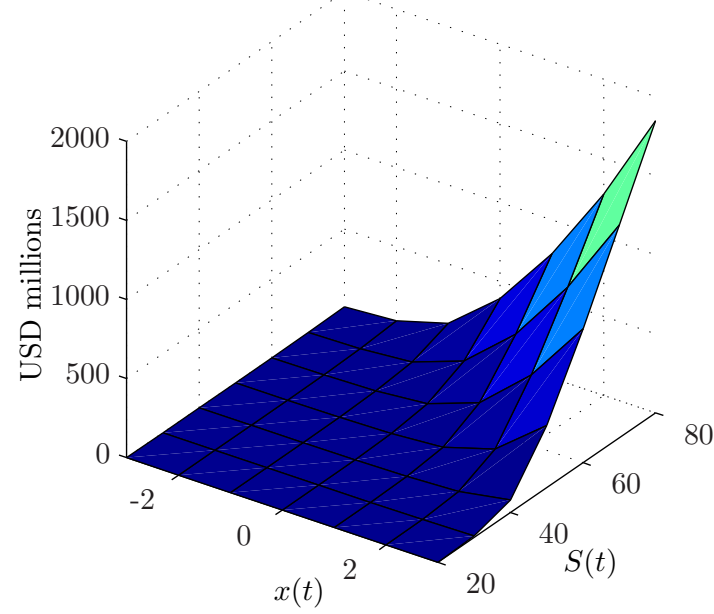

Panel C: Increase in GOv. value

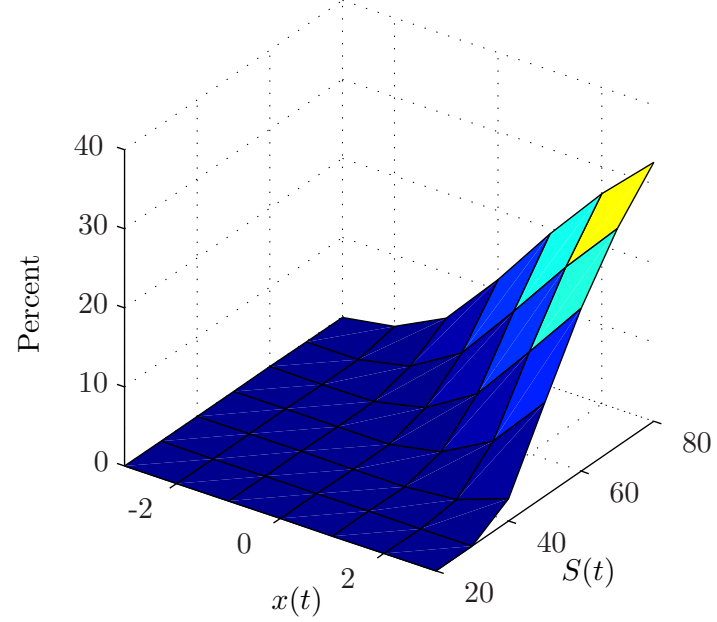

Panel B: "Deadweight loss"

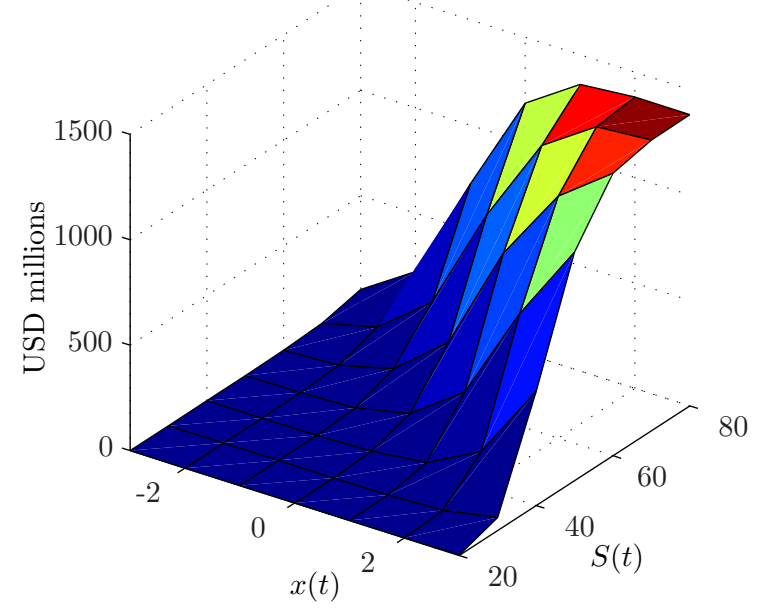

Panel D: Decrease in firm value

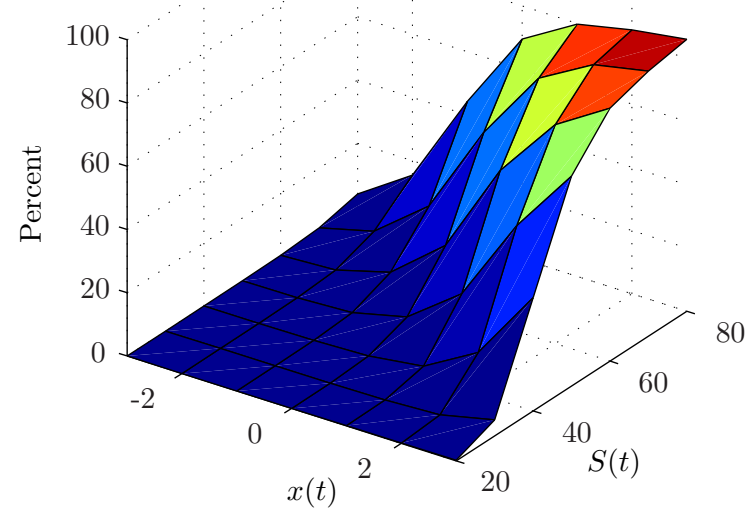

Figure 3: Expropriation risk as a function of $S(t)$ and $x(t)$

Panel A shows the value of the expropriation option, i.e. $P\left(t_{0}\right)$. Panel B shows the "deadweight loss", i.e. $\left(V_{\text {gov }}\left(t_{0}\right)+V_{\text {firm }}\left(t_{0}\right)\right)-\left(V_{\text {gov }}^{\text {exp }}\left(t_{0}\right)+V_{\text {firm }}^{\text {exp }}\left(t_{0}\right)\right)$. Panel C shows the percentage increase in the oil field's value to the government when taking into account the expropriation possibility, i.e. $V_{\text {gov }}^{\exp }\left(t_{0}\right) / V_{\text {gov }}\left(t_{0}\right)-1$. Panel D shows the percentage decrease in the oil field's value to the firm when taking into account the expropriation possibility, i.e. $-\left(V_{\text {firm }}^{\text {exp }}\left(t_{0}\right) / V_{\text {firm }}\left(t_{0}\right)-1\right)$. 
Panel A: Option value

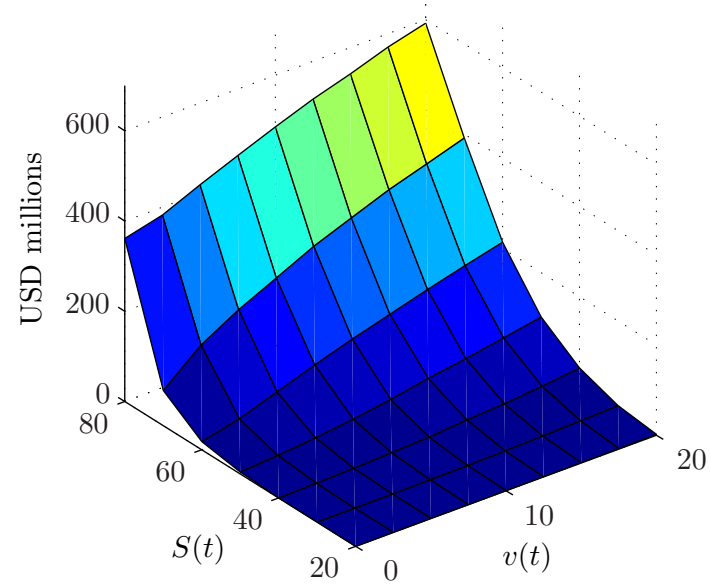

Panel C: Increase in gov. value

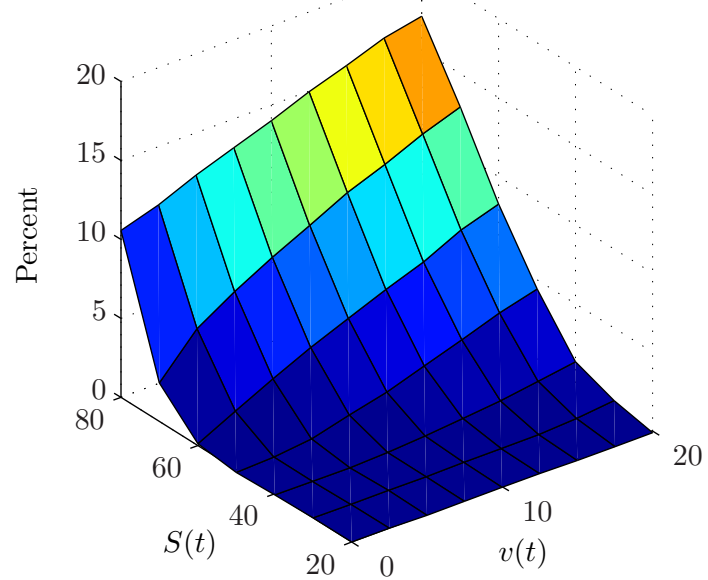

Panel B: "Deadweight loss"

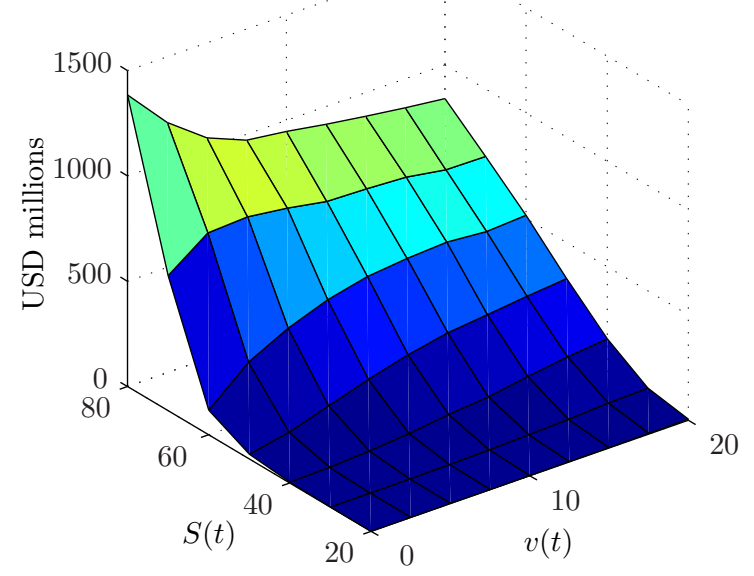

Panel D: Decrease in firm value

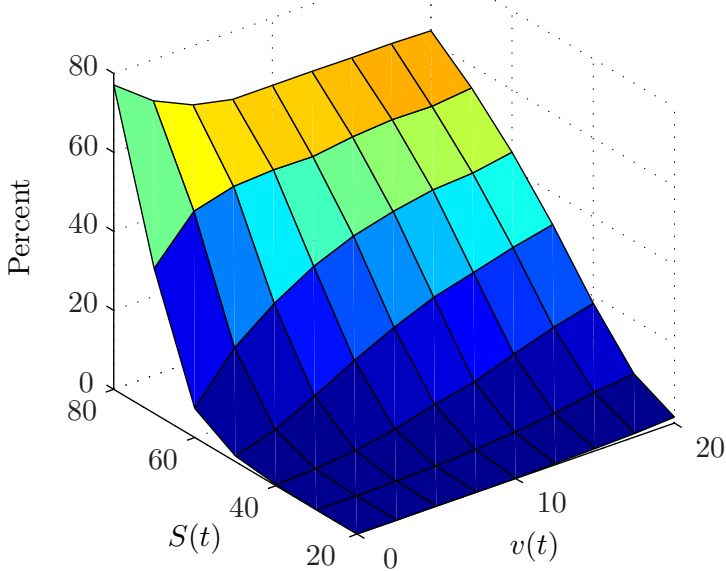

Figure 4: Expropriation risk as a function of $S(t)$ and $v(t)$

Panel A shows the value of the expropriation option, i.e. $P\left(t_{0}\right)$. Panel B shows the "deadweight loss", i.e. $\left(V_{\text {gov }}\left(t_{0}\right)+V_{\text {firm }}\left(t_{0}\right)\right)-\left(V_{\text {gov }}^{\text {exp }}\left(t_{0}\right)+V_{\text {firm }}^{\text {exp }}\left(t_{0}\right)\right)$. Panel C shows the percentage increase in the oil field's value to the government when taking into account the expropriation possibility, i.e. $V_{\text {goo }}^{\text {exp }}\left(t_{0}\right) / V_{\text {gov }}\left(t_{0}\right)-1$. Panel D shows the percentage decrease in the oil field's value to the firm when taking into account the expropriation possibility, i.e. $-\left(V_{\text {firm }}^{\text {exp }}\left(t_{0}\right) / V_{\text {firm }}\left(t_{0}\right)-1\right)$. 
Panel A: Option value

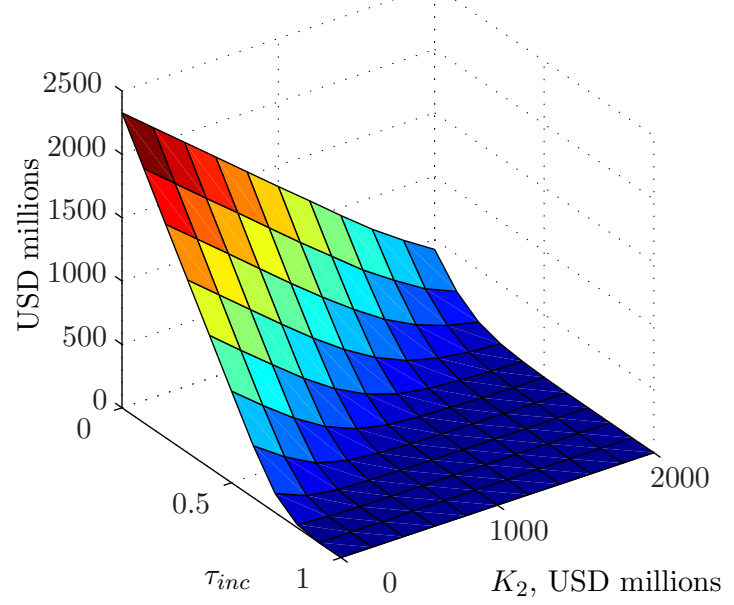

Panel C: Increase in Gov. value

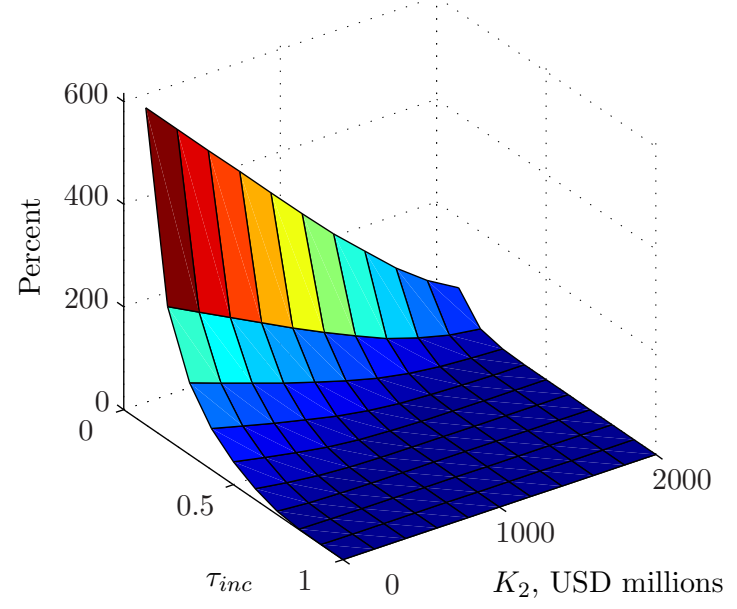

Panel B: "Deadweight loss"

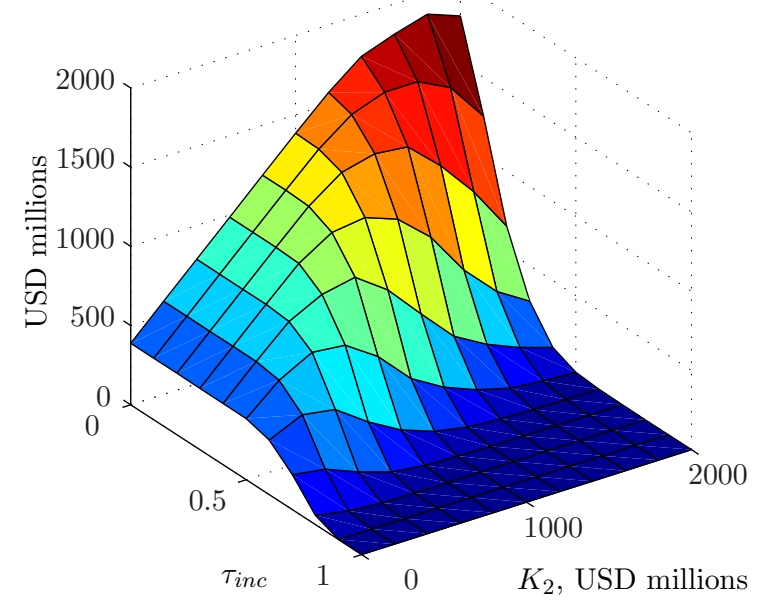

Panel D: Decrease in firm Value

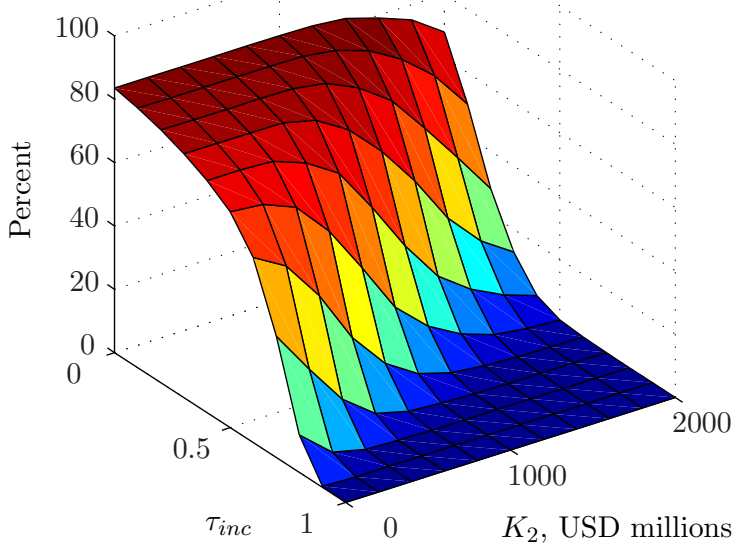

Figure 5: Expropriation risk as a function of tax rate and "reputational" costs

Panel A shows the value of the expropriation option, i.e. $P\left(t_{0}\right)$. Panel B shows the "deadweight loss", i.e. $\left(V_{\text {gov }}\left(t_{0}\right)+V_{\text {firm }}\left(t_{0}\right)\right)-\left(V_{\text {gov }}^{\text {exp }}\left(t_{0}\right)+V_{\text {firm }}^{\text {exp }}\left(t_{0}\right)\right)$. Panel C shows the percentage increase in the oil field's value to the government when taking into account the expropriation possibility, i.e. $V_{\text {goo }}^{\text {exp }}\left(t_{0}\right) / V_{\text {gov }}\left(t_{0}\right)-1$. Panel D shows the percentage decrease in the oil field's value to the firm when taking into account the expropriation possibility, i.e. $-\left(V_{\text {firm }}^{\text {exp }}\left(t_{0}\right) / V_{\text {firm }}\left(t_{0}\right)-1\right)$. 
Panel A: Option value

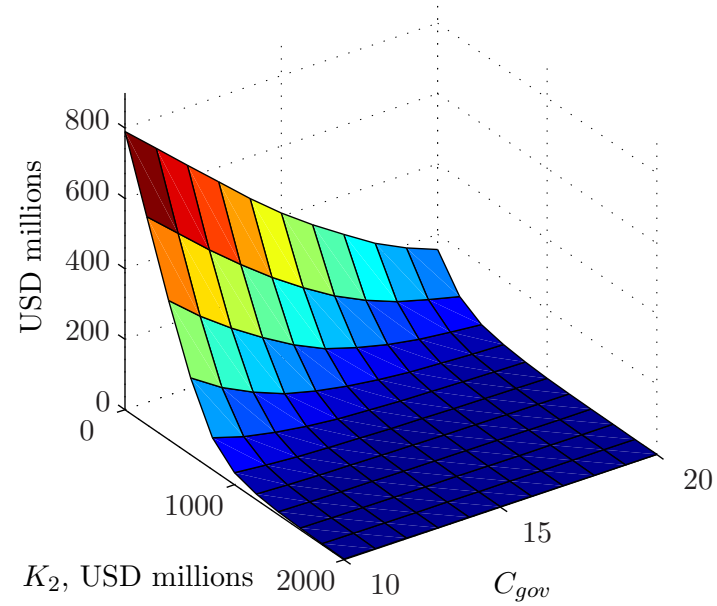

Panel C: InCREASE in GOV. VAlue

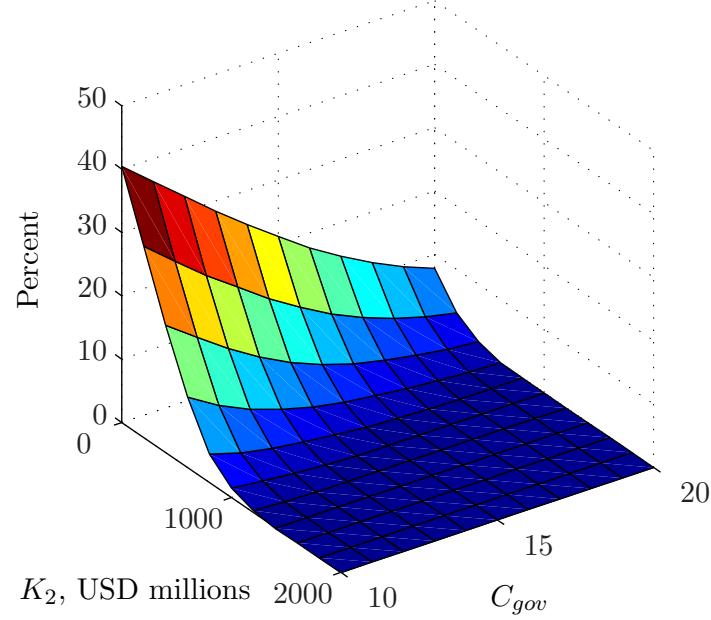

PANel B: "Deadweight LOSS"

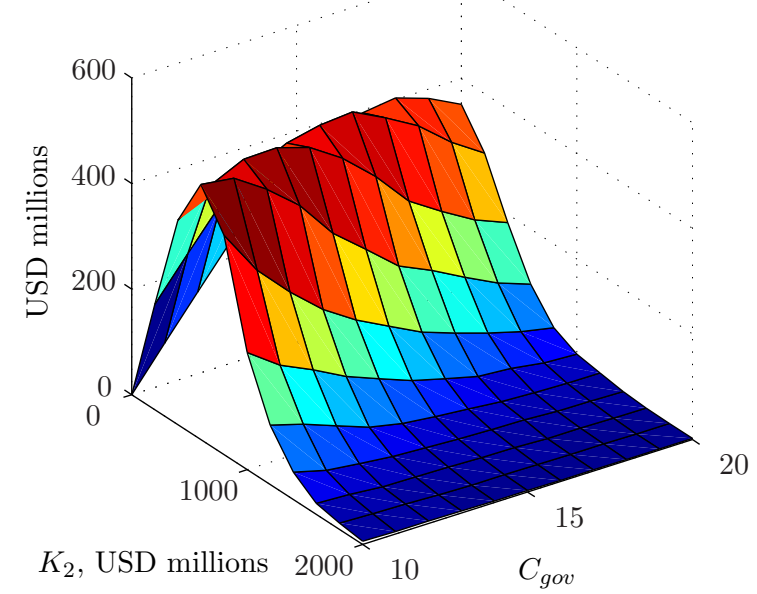

PANel D: DeCREASE IN FiRM VAlue

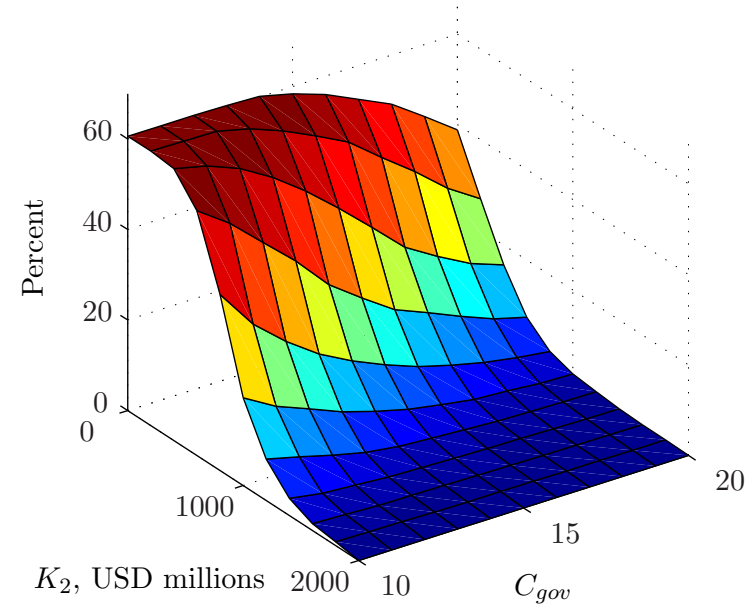

Figure 6: Expropriation risk as a function of "reputational" costs and state-run company's production cost

Panel A shows the value of the expropriation option, i.e. $P\left(t_{0}\right)$. Panel B shows the "deadweight loss", i.e. $\left(V_{\text {gov }}\left(t_{0}\right)+V_{\text {firm }}\left(t_{0}\right)\right)-\left(V_{\text {gov }}^{\text {exp }}\left(t_{0}\right)+V_{\text {firm }}^{\text {exp }}\left(t_{0}\right)\right)$. Panel C shows the percentage increase in the oil field's value to the government when taking into account the expropriation possibility, i.e. $V_{\text {gov }}^{\exp }\left(t_{0}\right) / V_{\text {gov }}\left(t_{0}\right)-1$. Panel D shows the percentage decrease in the oil field's value to the firm when taking into account the expropriation possibility, i.e. $-\left(V_{\text {firm }}^{\text {exp }}\left(t_{0}\right) / V_{\text {firm }}\left(t_{0}\right)-1\right)$. 
Panel A: Royalty tax equivalent

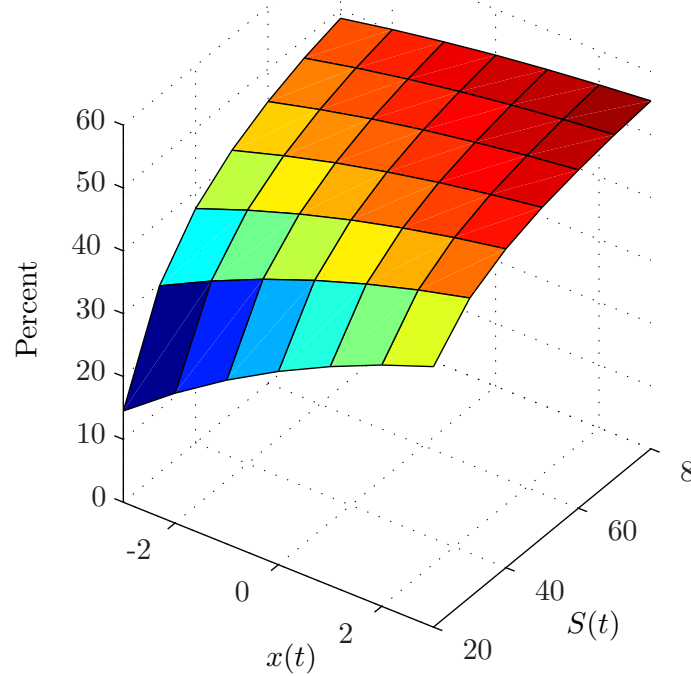

Panel B: Change in option value

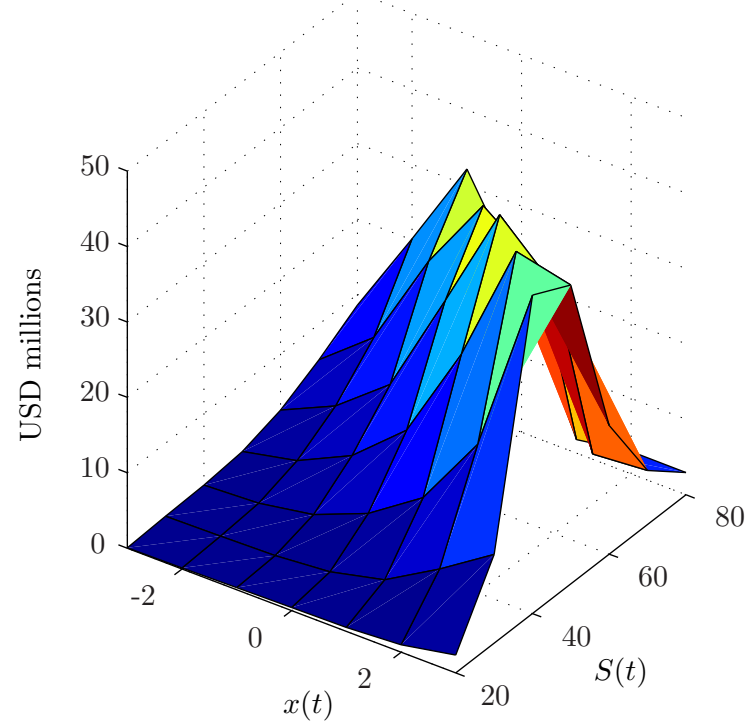

Figure 7: Change in option value when shifting from corporate income taxes to royalties

Panel A shows the $\tau_{\text {roy }}$ which, in the absence of expropriation risk, gives the same value of the oil field to the government as $\tau_{\text {inc }}=0.60$. Panel B shows $P_{\text {roy }}\left(t_{0}\right)-P_{\text {inc }}\left(t_{0}\right)$, where $P_{\text {roy }}\left(t_{0}\right)$ and $P_{\text {inc }}\left(t_{0}\right)$ denote the values of the expropriation option when the government relies exclusively on royalties and corporate income taxes, respectively. 


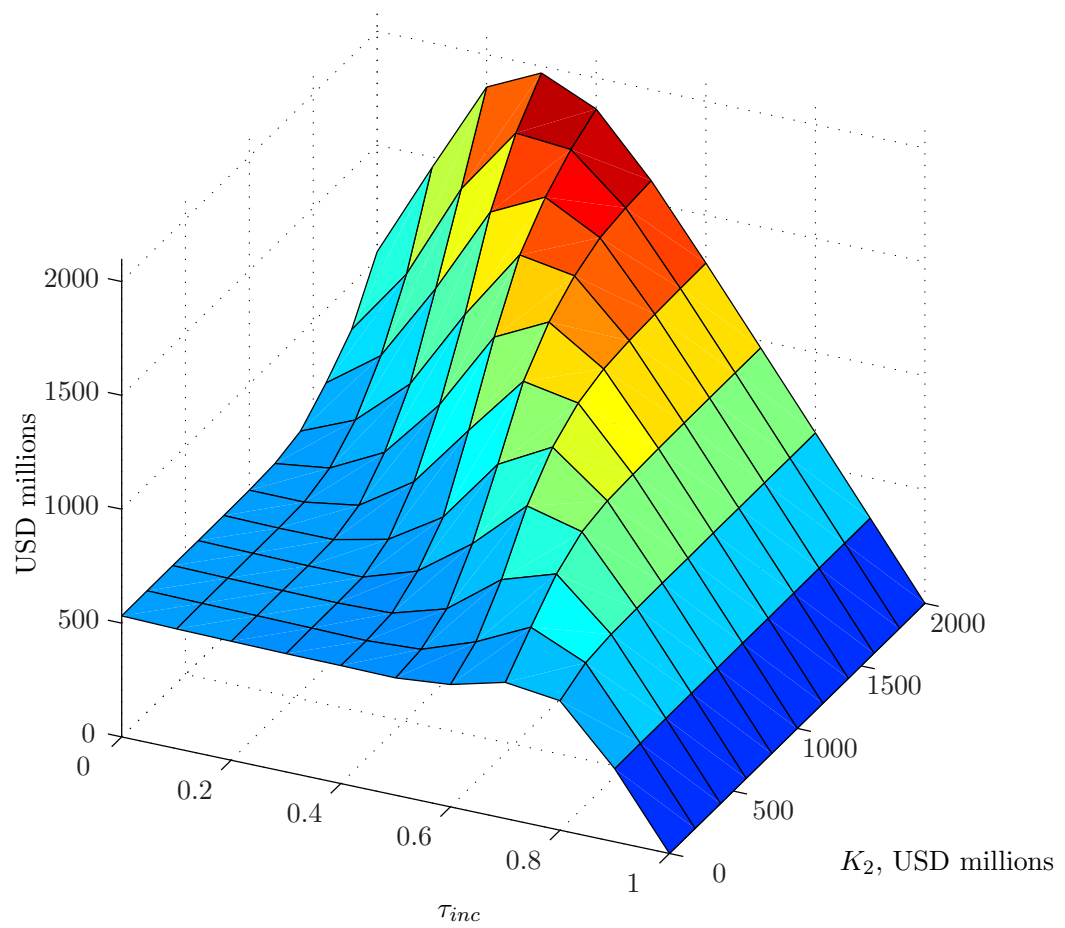

Figure 8: Oil field's value to the firm in the presence of expropriation risk as a function of tax rate and "reputational" costs

The figure shows the dollar value of the oil field to the firm in the presence of expropriation risk, i.e. $V_{f i r m}^{e x p}\left(t_{0}\right)$. 


\section{References}

Brennan, M. J. and E. S. Schwartz (1985): "Evaluating natural resource investments," Journal of Business, 58:135-157.

Clark, E. (2003): "Pricing the cost of expropriation risk," Review of International Economics, 11:412-422.

Clément, E., D. Lamberton, and P. Protter (2002): "An analysis of the least squares regression algorithm for American option pricing," Finance and Stochastics, 6:449-471.

DiXit, A. AND R. Pindyck (1994): Investment Under Uncertainty, Princeton University Press.

Engel, E. AND R. Fisher (2008): "Optimal resource extraction contracts under threat of expropriation," in this issue.

HARRISON, M. AND D. KREPS (1979): "Martingales and arbitrage in multiperiod securities markets," Journal of Economic Theory, 20:381-408.

HARrison, M. AND S. Pliska (1981): "Martingales and stochastic integrals in the theory of continuous trading," Stochastic Processes and Their Applications, 11:215-260.

Heath, D., R. Jarrow, and A. Morton (1992): "Bond pricing and the term structure of interest rates: A new methodology for contingent claims valuation," Econometrica, 60:77-105.

Longstaff, F. AND E. Schwartz (2001): "Valuing American options by simulation: A simple least-square approach," Review of Financial Studies, 14:113-147.

Mahajan, A. (1990): "Pricing expropriation risk," Financial Management, 19:77-86.

Rigobon, R. (2008): "Dealing with expropriations: General guidelines for oil production contracts," in this issue.

Schwartz, E. S. (1997): "The stochastic behavior of commodity prices: Implications for valuation and hedging," Journal of Finance, 52:923-973.

Trolle, A. B. And E. S. Schwartz (2007): "Unspanned stochastic volatility and the pricing of commodity derivatives," Working paper, UCLA and NBER \# 12744. 